\title{
Configurações
}

Revista de sociologia

$10 \mid 2012$

Políticas Públicas

\section{As políticas de educação pré-escolar e as parcerias entre o Estado e o terceiro setor}

Policies for Pre-School Education and partnerships between the State and the Third Setor

Les politiques de l'éducation préscolaire et les partenariats entre l'état et le secteur tertiaire

\section{Emília Vilarinho}

\section{(2) OpenEdition}

\section{Journals}

Edição electrónica

URL: http://journals.openedition.org/configuracoes/1422

DOI: $10.4000 /$ configuracoes. 1422

ISSN: 2182-7419

\section{Editora}

Centro de Investigação em Ciências Sociais

\section{Edição impressa}

Data de publição: 1 Dezembro 2012

Paginação: 109-122

ISBN: 1646-5075

ISSN: 1646-5075

\section{Refêrencia eletrónica}

Emília Vilarinho, «As políticas de educação pré-escolar e as parcerias entre o Estado e o terceiro setor », Configurações [Online], 10 | 2012, posto online no dia 17 fevereiro 2014, consultado o 20 abril 2019. URL : http://journals.openedition.org/configuracoes/1422 ; DOI : 10.4000/configuracoes. 1422

Este documento foi criado de forma automática no dia 20 Abril 2019.

(c) CICS 


\section{As políticas de educação pré-escolar e as parcerias entre o Estado e o terceiro setor}

Policies for Pre-School Education and partnerships between the State and the Third Setor

Les politiques de l'éducation préscolaire et les partenariats entre l'état et le secteur tertiaire

Emília Vilarinho

\section{Introdução}

1 Nas últimas três décadas, a Educação Pré-Escolar em Portugal tem sido objeto de múltiplas redefinições no que concerne à sua conceção, às funções sociais e à organização da rede de jardins de infância. Em 1997, a publicação da Lei-Quadro da Educação PréEscolar (Lei n.. 5/97, de 10 de fevereiro) marca o início de um novo ciclo de reestruturação deste nível de educação. Esta Lei-Quadro e o Decreto-Lei n.. 147/97, de 11 de junho, que a regulamenta, são definidos e publicados num quadro de uma conjuntura nacional e internacional em que são visíveis as crescentes influências dos processos de globalização e transnacionalização, com repercussões nas políticas educativas, e onde as reformas e orientações de índole neoliberal e de cariz próximo da terceira via revalorizam, em sentidos vários, os apelos e as medidas direcionadas para uma maior participação do mercado, da sociedade civil e do terceiro setor nas políticas públicas. Ora, o direito à educação é, desde a modernidade, uma condição de inclusão social; logo, num contexto internacional e nacional em que se observam, em simultâneo, redefinições da natureza, do papel e do lugar do Estado, as mudanças que aqui ocorrem têm influência na vida das crianças. 
2 Tomamos a Educação Pré-Escolar (EPE) como uma das componentes de uma política integrada para a infância promotora de inclusão social ${ }^{1}$, o que significa considerá-la como uma política social. Neste sentido, a conceção de Educação Pré-Escolar, o seu provimento e fornecimento estão intimamente ligados a variáveis estruturais e, nesta medida, as suas políticas estão também a ser influenciadas pelas mutações na economia, na política, no Estado e na relação deste com o Mercado e a sociedade civil, mudanças que radicam nos processos de globalização hegemónica e na emergência da "sociedade de risco".

\section{0 contexto político: Portugal a caminho de uma política de terceira via?}

3 A análise das intervenções políticas de governantes, dos programas de governo e das medidas implementadas leva-nos a concluir que, entre 1995 e 2002, durante os XIII e XIV Governos Constitucionais, o Partido Socialista ensaiou uma política ancorada em princípios e valores próximos daqueles que Giddens (1999) identificou como sendo os que configuram a terceira via. ${ }^{2} \mathrm{Na}$ linha das premissas da terceira via, o PS, não querendo relegar os valores do socialismo democrático, redefiniu a sua intervenção política colocando a tónica naqueles valores, na ética da responsabilidade, na solidariedade voluntária, no diálogo social, no combate à exclusão social, na coesão social e na cidadania solidária. $\mathrm{O}$ aprofundamento da democracia, com o reforço da participação da sociedade civil e das suas organizações na comunidade é também um vetor importante do discurso governamental. A defesa da concretização de parcerias entre o Estado e as organizações da sociedade civil tendentes ao bem-estar das comunidades é entendida como forma de melhorar a governação e, simultaneamente, reforçar naquelas organizações o sentido da ética e da responsabilidade do serviço público.

4 É neste contexto que, na Assembleia da República, é apresentado o Pacto Educativo para o Futuro pelo Ministro da Educação, Marçal Grilo, e é assinado o Pacto de Cooperação para a Solidariedade Social. Trata-se de dois instrumentos fundamentais de definição das políticas sociais e educativas, que vão permitir um novo relacionamento do Estado com a sociedade civil

5 No que diz respeito ao Pacto Educativo para o Futuro recordamos o apelo à mobilização cívica pela causa da educação e a redefinição do papel do Estado, justificada pela importância e necessidade de assegurar uma maior participação dos parceiros sociais nas decisões e na execução das políticas educativas. Como afirma A Afonso (2009: 22), referindo-se àquele documento, "é também o próprio papel do Estado que é posto em causa porque se pretende que este deixe de ter centralidade necessária na promoção da educação pública". Relativamente às políticas de Educação Pré-Escolar, o Estado assume, desta forma, os papéis de mobilizador, mediador e regulador do sistema e não o de principal promotor do provimento da educação pública, parecendo relegar para segundo plano o papel que lhe é conferido pela Constituição da República Portuguesa e pela Lei de Bases do Sistema Educativo.

o Pacto de Cooperação para a Solidariedade Social (PCSS) serviu de "chapéu" para a conceção do novo quadro regulador da Educação Pré-Escolar, para a implementação do Programa de Expansão e Desenvolvimento da Educação Pré-Escolar, bem como para a alteração dos Acordos de Cooperação entre o Estado e as IPSS. 


\section{A agenda, os valores e os instrumentos do novo projeto para a Educação Pré-Escolar}

7 A Lei-Quadro da Educação Pré-Escolar e o Decreto-Lei n.ำ 147/97, de 11 de junho, são as bases da construção de um novo "edifício" político, concetual e organizacional deste nível de educação. Ao processo de construção daquela lei e decreto-lei não foi alheio o contributo dos diferentes parceiros sociais que assinaram com o Governo o Pacto de Cooperação para a Solidariedade Social e cujos princípios acordados foram observados nesta regulamentação. É também de salientar a audição pública de várias outras entidades, como os representantes das organizações sindicais de professores, das organizações representativas do ensino particular e cooperativo e das associações de pais. Ao legislar, o Governo parece ter correspondido aos compromissos assumidos com os diferentes parceiros, de modo a não defraudar a confiança em si depositada aquando do estabelecimento da "coligação da causa pela Educação Pré-Escolar".

Neste artigo, apresentamos, de forma breve, os principais aspetos que materializam os pressupostos políticos, educacionais e organizacionais da Lei-Quadro, em três campos de análise: A - Objetivos, Conceção e Modelo Organizacional; B - Princípios Organizativos; CPapel do Estado, Planeamento e Financiamento da Rede. Com este exercício, em que cotejamos os dois documentos legislativos referidos, pretendemos evidenciar as continuidades entre eles (coerência/incoerência), as explicitações, as estratégias e os instrumentos para a sua implementação, bem como dar conta dos "ajustamentos" operados no decreto-lei que são reveladores do confronto e dos compromissos entre os princípios, os valores e os interesses dos diferentes atores institucionais em presença Estado/Terceiro Setor. Desta forma, damos conta de elementos do contexto da produção do texto da política (Bowe, Ball \& Gold 1992) da Educação Pré-escolar.

\section{A - Objetivos, Conceção e Modelo organizacional}

9 Os pressupostos justificativos da importância das medidas a implementar assentam na relevância que diferentes países da União Europeia têm dado a este nível de educação nas suas políticas educativas, sociais e económicas, bem como nos resultados da investigação científica, que têm revelado que a frequência de programas de Educação de Infância de qualidade é fundamental para o desenvolvimento e integração social das crianças. Neste sentido é reforçada a sua função educativa e a EPE é definida como a $1^{\mathrm{a}}$ etapa da Educação Básica.

10 O grande objetivo estratégico plasmado no decreto-lei no. 147/97 é criar as condições para o lançamento efetivo do Programa de Expansão e Desenvolvimento da Educação PréEscolar "que corresponda às necessidades educativas e concretize o princípio da igualdade de oportunidades" e que materialize o direito das crianças à educação, consignado na Constituição Portuguesa e na Convenção dos Direitos das Crianças. Do decreto-lei ressaltam duas grandes prioridades governamentais: a promoção da qualidade dos serviços e o alargamento das taxas de pré-escolarização - aumentar "até ao final do século, a oferta global de Educação Pré-Escolar em cerca de 20\%, de modo a abranger $90 \%$ das crianças de cinco anos de idade, $75 \%$ das de quatro anos de idade e $60 \%$ das de três anos de idade, alargando a possibilidade de frequência a mais 45000 crianças nesta faixa etária". Com estas prioridades pretende-se a obtenção de igualdade de oportunidades 
educativas, de modo a que "a Educação Pré-Escolar não constitua um privilégio mas um direito, integrado na realização do objetivo afirmado pela UNESCO de que a Educação é para todos" (D.L. n. ${ }^{147 / 97) . ~}$

11 A "agenda" é assim definida integrando dois movimentos: a expansão quantitativa do sistema e a expansão qualitativa do mesmo. A preocupação com o desenvolvimento de uma Educação Pré-Escolar de qualidade nas duas redes é, naquele decreto apresentada de forma mais explícita, sendo fundamentadas as razões da sua importância e definidas algumas regras tendentes à promoção da qualidade educativa dos jardins de infância ${ }^{3}$. No que concerne ao acesso a este bem educativo, o referido decreto reforça a intencionalidade de tornar efetivo o direito de acesso gratuito à componente educativa $\mathrm{e}$ de criar as condições de acesso iguais, independentemente dos rendimentos das famílias e da natureza pública/privada dos jardins de infância. A redação do artigo relativo à igualdade de oportunidades é bastante esclarecedora das intenções governamentais relativamente a esta matéria: "Para efeitos do presente diploma, a igualdade de oportunidades implica, nomeadamente, que as famílias, independentemente dos seus rendimentos, beneficiem das mesmas condições de acesso, qualquer que seja a entidade titular do estabelecimento de Educação Pré-Escolar" (Artigo 7º, ponto 1). Estamos na presença do reassumir de um compromisso político de extrema relevância para a concretização dos objetivos propostos perante as famílias e a sociedade em geral.

Ao nível do modelo organizacional é reforçada a perspetiva do modelo integrado de educação e cuidados, sendo os jardins de infância concebidos como serviços sócioeducativos de resposta às necessidades das crianças e das suas famílias. Para a materialização deste modelo é alargado o horário de funcionamento dos jardins de infância públicos e criada a componente sócio-educativa de apoio à família4a .

\section{B - Princípios Organizativos}

Nesta dimensão são introduzidas mudanças significativas. Aquela que nos parece ter um maior alcance, imediato e futuro, e que revela pressões económicas e cooperativas provenientes de vários setores, é a fixação do número mínimo e máximo de frequência das crianças por sala de jardim de infância (mínimo de 20 e máximo de 25). Recorde-se que esta definição já estivera presente na proposta de Lei-Quadro e não obtivera consenso. No decreto-lei há a preocupação de salvaguardar as zonas de fraca densidade populacional. A fixação do número máximo de crianças por sala consubstancia uma das medidas ativas de promoção da qualidade educativa, contemplada e genericamente respeitada desde a sua criação, pelos jardins de infância da rede pública mas nem sempre observada na rede privada. Desta forma, o Estado controla os custos do fornecimento do serviço educativo e intervém diretamente na gestão da rede, impondo, igualmente, critérios de salvaguarda da qualidade dos serviços prestados. Do lado dos representantes das instituições privadas (com e sem fins lucrativos) houve sempre receios em relação a esta prescrição normativa. Para os representantes da rede privada com fins lucrativos, com jardins de infância dominantemente localizados nas áreas metropolitanas de Lisboa e Porto e nas cidades onde a concorrência da rede pública é quase inexistente, aquela prescrição é uma limitação aos interesses financeiros das mesmas. Os representantes da rede privada sem fins lucrativos, cujos jardins de infância se distribuem não só pelas grandes áreas metropolitanas e cidades mas também por zonas geográficas com menor população, receando a deslocação das crianças para os jardins de infância públicos (agora 
com extensão de horário), vêem naqueles números de frequência, em particular no número mínimo, uma ameaça ao corte de financiamento das salas que não cumpram com os requisitos.

Um outro aspeto relevante é o reforço da especificidade educativa pela atribuição da coordenação da componente sócio-educativa aos educadores de infância titulares de sala nos jardins públicos e da valorização das competências profissionais no campo da educação para a direção pedagógica dos jardins de infância nos jardins privados. Se, na rede pública, a formação académica e profissional do(s) elemento(s) do órgão de direção nunca se colocou, na rede privada, esta questão sempre suscitou sempre alguns problemas entre profissionais e dirigentes. A história das instituições privadas foi fortemente marcada pela prestação de um serviço social às famílias, pelo que o cargo de coordenação técnica (e não o direção) foi quase sempre assumido por uma assistente social. Por outro lado, o facto de nas instituições privadas coexistirem a creche e o jardim de infância, aquela decisão obrigou, no caso de a coordenação técnica ser assumida por um outro profissional, à reorganização dos serviços e, em muitos casos, à coexistência de diferentes "coordenações" em serviços que têm os mesmos destinatários - as crianças. Este aspeto introduziu uma nova fragmentação nos serviços para a infância, reforçando os recortes de idades da primeira infância (0-2anos/3-5/6 anos) e as imagens sociais e educativas das crianças -sujeito pré-cultural/sujeito cultural (Chamboredon e Prévot, 1982; Vilarinho, 2000).

\section{C - Planeamento e Financiamento da Rede}

O Decreto-Lei n. 147/97 apresenta um novo ordenamento das redes, criando a Rede Nacional de Educação Pré-Escolar, que integra as redes pública e privada, visando a universalização e a qualidade da oferta (introdução e artigo $3^{\circ}$, ponto 1). Desta forma, o decreto-lei explicita o entendimento de redes de Educação Pré-Escolar que, até então, atravessava os discursos políticos mas que não estava consagrado em documentos normativos. No texto introdutório do decreto-lei pode ler-se:

o desenvolvimento de uma Educação Pré-Escolar de qualidade constitui, assim, o objetivo central do presente diploma, devendo materializar-se na criação de uma rede nacional de Educação Pré-Escolar, integrando uma rede pública, constituída a partir da iniciativa da administração central e local, e uma rede privada, desenvolvida a partir das iniciativas das instituições particulares de solidariedade social, dos estabelecimentos de ensino particular e cooperativo e de outras instituições sem fins lucrativos que prossigam atividades no domínio da educação e do ensino.

Ao nível do planeamento e expansão da Rede Nacional, as prioridades de financiamento são congruentes com o problema diagnosticado a priori, relacionado com as assimetrias regionais de cobertura. São criados incentivos financeiros para a construção, ampliação e remodelação dos estabelecimentos de Educação Pré-Escolares em zonas carenciadas. Verifica-se também congruência com a conceção de Educação Pré-Escolar como primeira etapa da Educação Básica e com a função educativa e compensatória das desigualdades sociais de acesso à educação escolar, uma vez que é também previsto o apoio financeiro a estabelecimentos de Educação Pré-Escolar que se localizem em zonas de risco de exclusão social e escolar e em zonas onde se observam elevados índices de insucesso escolar. Os apoios financeiros previstos estão também condicionados à natureza das entidades promotoras, observando-se uma discriminação positiva em relação aos municípios (que 
têm competências delegadas na rede pública) e às instituições privadas sem fins lucrativos. A discriminação em relação a estas instituições ilustra a influência dos signatários do Pacto para a Solidariedade, que reclamam um estatuto diferente das entidades privadas. As instituições particulares de solidariedade social, as misericórdias e as mutualidades veem reforçado o seu estatuto de parceiros privilegiados, e a chamada rede privada solidária passa a ter, a partir deste momento, uma melhor atenção no financiamento estatal.

O papel do Estado na expansão e desenvolvimento da Educação Pré-Escolar é, assim, redefinido, quer ao nível das suas relações internas (interministeriais), quer ao nível das relações com as outras entidades que fornecem estes serviços. As definições relativas às tutelas pedagógica e técnica e às articulações interministeriais (ME e MTS) que têm de ser implementadas são os meios encontrados pelo XIII Governo para tentar resolver um dos grandes problemas identificados nos diferentes diagnósticos da realidade da Educação Pré-Escolar portuguesa - a fragmentação concetual e institucional do sistema. Simultaneamente, o Estado estende a sua ação reguladora a áreas da rede privada, onde a sua intervenção era bastante frágil, como é o caso do currículo e da organização pedagógica do jardim de infância.

A partir da publicação deste Decreto-Lei nº. 147/97, no período entre 1997 e 1999, o Estado vai reforçar o seu poder regulador, criando instrumentos de regulação institucional de cariz jurídico-burocrático em áreas como a edificação dos edifícios, a organização pedagógica, o apetrechamento de equipamentos e materiais pedagógicos, o currículo, entre outros. Desta forma, o Estado chama a si a responsabilidade social de definição do quadro regulador das políticas de Educação Pré-Escolar, ao mesmo tempo que incentiva e delega nas instituições da sociedade civil a promoção direta de criar novos jardins de infância. A análise do contexto de produção dos textos políticos (Bowe, Ball e Gold, 1992; Ball, 1994) - Lei no. 5/97 e Decreto-Lei no. 147/97 - permite-nos observar melhor aquela tendência. Este facto é ilustrado pela assunção da tutela pedagógica (única) pelo Ministério da Educação, reforçada pelas Orientações Curriculares para a Educação PréEscolar, pelo controle da qualidade através de mecanismos de avaliação, supervisão e inspeção e ainda pelo estabelecimento de regras de financiamento. Ou seja, o Estado, ao mesmo tempo que promove a liberalização do fornecimento por meio de autorizações de funcionamento, mantém o controlo, quer sobre o produto, quer sobre o serviço. Como refere Roger Dale (1994: 116), o Estado é como que uma "sentinela", pois é ele que se assume como "responsável político único para garantir que a educação de alcance e qualidade esteja disponível para todas as crianças".

Na conceção do novo projeto de Educação Pré-Escolar constatamos a presença de alguns elementos de proximidade às políticas da terceira via. Uma primeira constatação é que o governo socialista propôs-se desenvolver e expandir a oferta educativa de forma diferente. Um conjunto de argumentos denotativos da diferença prende-se com a própria redefinição da rede. Em primeiro lugar, a alteração de uma rede pública gratuita e uma rede privada não gratuita autónomas para uma rede nacional que integra ambas as redes e onde o Ministério da Educação, pela primeira vez, assume a tutela pedagógica de ambas; em segundo lugar, o facto de a expansão da oferta não ser unicamente feita pela rede pública, incentivando-se a diversificação da mesma através da mobilização da sociedade civil, em particular, da rede solidária do terceiro setor e, em terceiro lugar, a ação de se legislar a gratuitidade da componente letiva para a rede solidária e a comparticipação familiar da componente de apoio à família em ambas as redes. Este último aspeto é aquele 
que se reveste de maior novidade e importância. A estratégia de expansão passou pela mobilização do terceiro setor. A rede solidária, pela via da contratualização, tornou-se pública e, neste sentido, o Estado, pelo menos em termos formais, garantiu o acesso gratuito à componente educativa da Educação Pré-Escolar. No entanto, ao criar um novo modelo organizacional para os jardins de infância da rede pública, com a extensão de horário, não salvaguardou a gratuitidade da componente de apoio à família. Deste modo, questionamos quais os efeitos práticos desta medida, no que concerne à promoção da igualdade de acesso à Educação Pré-Escolar.

Uma segunda constatação é a de que nos dois ciclos de governação do Partido Socialista se observou uma recomposição do Estado, onde o Terceiro Setor ganhou mais visibilidade e protagonismo na implementação de políticas sociais e onde o Estado remeteu para si próprio, os papéis de Regulador, de Avaliador e Articulador. Naquele ciclo político, o Estado parece ter tido como preocupação central a edificação do projeto assente num quadro normativo extenso, que regulasse as diferentes dimensões do desenvolvimento do projeto, instituindo formas diferentes de coordenação, controlo e governação da rede nacional de Educação Pré-Escolar.

21 A terceira constatação é a de que os Governos socialistas (à semelhança do que aconteceu no Reino Unido, com Tony Blair) solicitaram apoio a especialistas da área da Educação da Infância para a conceção das grandes linhas estratégicas das políticas pré-escolares e para integrar o Conselho Consultivo do Gabinete Interministerial para a Expansão e Desenvolvimento da Educação Pré-escolar (GIEDEPE). Recordamos aqui o pedido feito a João Formosinho e a Teresa Vasconcelos para a elaboração do Plano Estratégico de Expansão e Desenvolvimento da Educação Pré-Escolar, bem como a presença de João Formosinho e de Bairrão Ruivo no referido conselho consultivo do GIEDEPE. Esta colaboração revelou-se fundamental, em especial, para o fortalecimento da função educativa da Educação Pré-Escolar, para o respeito pela sua especificidade pedagógica e para o reforço da identidade e valorização profissional dos educadores de infância. Por outro lado, a aliança conjuntural entre a Academia e o Governo foi importante para legitimar na opinião pública as medidas que se pretendiam implementar. A presença de elementos representantes dos interesses da rede solidária do terceiro setor no conselho consultivo do GIECEPE serviu também a estratégia governamental na mobilização da sociedade civil, obtenção de credibilidade e conquista da confiança dos parceiros sociais. Por outro lado, o terceiro setor ganhou um novo estatuto e reforçou o seu poder negocial.

Em síntese, pela análise aqui produzida, poderemos afirmar que, pelo menos em algumas áreas, o discurso político justificativo da implementação de novas políticas aproximou-se da orientação política da terceira via. No entanto, o facto de os discursos se direcionarem naquela orientação política não significa que tenham produzido os efeitos pretendidos na prática. Os discursos políticos cumprem, muitas vezes, a função de dar credibilidade e legitimidade às políticas que se implementaram ou se pretendem implementar. Por outro lado, como refere S. Ball (2007: 2), "os discursos da reforma têm efeitos distintivos mas estes efeitos não são determinados, nem facilmente previsíveis, nem trabalhamde forma independente de outros mecanismos extradiscursivos". No cenário de globalização neoliberal, a experiência de alguns países revela que o Estado tem incentivado a criação de redes e de alianças necessárias para que sejam salvaguardados os direitos sociais. Contudo, o Estado não se pode substituir à sociedade civil na prestação de serviços de proteção social e de educação, sob pena de aqueles direitos serem fragilizados. Como alguns críticos da ideia da terceira via têm referido, a sua argumentação pode não passar 
de um discurso retórico que encobre a retração do Estado e não rompe com a ideologia neoliberal. Assim, é importante desenvolver trabalhos empíricos para se compreender a relação entre os discursos, a sua implementação e os efeitos das medidas promovidas.

No tópico seguinte apresentamos alguns dos resultados de um estudo de caso da implementação da componente sócio-educativa de apoio à família em jardins de infância públicos, realizado no período compreendido entre 2003 e 2010 no concelho de Mareantes, situado no Norte de Portugal. Neste estudo utilizamos como técnicas de recolha de informação a observação não participante, a análise documental e a entrevista semiestruturada, sendo esta última tratada através da análise de conteúdo. Identificamos os atores significativos e agrupamo-los em três grupos, tendo em conta a especificidade do lugar e o papel que cada grupo de atores assume na implementação das políticas: Grupo I - Representantes políticos regionais e representantes nacionais das organizações do terceiro setor; Grupo II - Representantes políticos e das estruturas educativas locais; Grupo III - Presidentes de entidades locais parceiras na implementação da CAF.

Com este estudo aproximamo-nos do contexto da prática e do contexto dos resultados/efeitos (cf. Ball \& Bowe, 1992; Ball, 1994), que nos permitiu apreender e compreender, por um lado, as interpretações e a recriação a que a política original de educação esteve sujeita e, por outro, os efeitos produzidos por aquela medida política.

\section{Um novo padrão de governação da Educação Pré- Escolar em Mareantes}

25 A componente sócio-educativa de apoio à família (CAF), nos jardins de infância da rede pública introduziu maior complexidade organizacional aos jardins de infância, alargou a possibilidade da participação da sociedade civil na implementação e organização da mesma e trouxe novos problemas que nos interessou identificar e analisar.

No Protocolo de Cooperação celebrado em 28 de julho de 1998, entre os Ministérios da Educação e do Trabalho e da Solidariedade, a Associação Nacional de Municípios Portugueses e os representantes das instituições sociais, são definidas responsabilidades aos diversos parceiros, sendo da competência dos Municípios a operacionalização desta componente, no que diz respeito a espaços, recursos humanos e materiais.

O Município de Mareantes optou por delegar competência nas entidades e organizações das freguesias. Esta opção promoveu a emergência da diversificação de modalidades e padrões de governação, levando à ocorrência do efeito de mosaico (cf. Barroso, 2003) naquele território. Por outro lado, o governo dos jardins de infância públicos é partilhado entre parceiros que, até há pouco tempo, estavam de costas voltadas. Apesar do empenho e vontade de todos, foram identificados alguns problemas, muitos deles decorrentes da frágil relação institucional. Verificamos, por exemplo, que no que diz respeito à coordenação da CAF, os educadores estiveram muito tempo ausentes. Esta ausência foi tacitamente aceite pelos parceiros que, no fundo, desejavam a manutenção desta situação. Contudo, ela propiciou o desenvolvimento de serviços de qualidade variável que se traduziram em desigualdades de condições oferecidas às crianças. A assunção daquela coordenação aparece gradualmente ao longo dos anos, à medida que os educadores de infância e os Agrupamentos de escolas tomam consciência profissional e institucional da sua importância. Será através do Despacho n.ำ 14460/2008, de 26 de maio, que define as normas a observar na oferta das atividades de enriquecimento curricular e de animação e 
de apoio à família (1e ciclo e EPE), que os Agrupamentos de escolas vão encontrar legitimação para contrariar práticas e lógicas de ação autónomas das entidades parceiras, no que concerne à planificação das atividades de animação sócioeducativas. Financiamento e os efeitos de 2. ${ }^{\text {a }}$ ordem (Ball, 2004)

A EPE tem cofinanciamento do Estado e das famílias, sendo que a comparticipação familiar só se aplica à frequência da CAF. Os mecanismos e instrumentos de financiamento estão regulamentados e plasmados no protocolo de cooperação celebrado entre os diferentes parceiros. Nas entrevistas que nos concederam, os presidentes da União das Misericórdias Portuguesas e da Confederação Nacional das Instituições Sociais e a diretora do Centro Distrital de Segurança Social levantaram questões em relação aos diferentes procedimentos de atribuição da comparticipação familiar, adotados em diferentes municípios.

29 A relevância deste assunto face aos seus efeitos, quer na consolidação das duas redes (pública e solidária), quer no que concerne à igualdade de acesso à EPE, fez-nos estar mais atentos a ele ao nível local. No que diz respeito à comparticipação estatal, os dados são objetivos: os valores elegíveis são transferidos para o Município que, por sua vez, transfere para as entidades parceiras.

Em relação às comparticipações familiares, a recolha de informação tornou-se muito difícil. O município não sabe em concreto que procedimentos as entidade parceiras estão a adotar, apesar de no protocolo assinado entre ambos impor o cumprimento do Despacho Normativo Conjunto n $300 / 97$. Da parte dos nossos entrevistados, verificamos que existiam muitas hesitações e imprecisões relativamente às comparticipações pagas pelas famílias. Pelo cruzamento de dados conseguimos apurar a realidade, constatando que: em dezasseis jardins de infância públicos, dez aplicam um valor único (entre 67,12 $€ \mathrm{e}$ $100 €$ ); em três jardins existe uma tabela com seis escalões (valores máximos entre $90 € \mathrm{e}$ $62,50 €$ e valores mínimos entre $50 €$ e $32,50 €$ ); um jardim tem uma tabela com três escalões $(65 €, 70 €$, e $80 €)$; e num jardim de infância as crianças só pagam as refeições pelo valor legalmente previsto $(32,12 €)$ sendo as atividades de animação gratuitas.

31 Esta realidade configura uma infidelidade normativa (Lima, 1992) na aplicação da comparticipação familiar. 0 espírito da lei vai no sentido da discriminação positiva das crianças provenientes de famílias com rendimentos baixos. O valor único e mesmo os escalões atribuídos sem ter em conta a diferenciação por escalões de rendimentos per capita, prescrita no Despacho Normativo, são indicadores do desrespeito pelo princípio de discriminação positiva. Este facto levanta questões muito sérias em relação à igualdade de acesso das crianças à frequência da EPE. Os responsáveis pelas entidades parceiras, bem como os dirigentes dos agrupamentos de escolas revelaram não ter consciência dos efeitos produzidos e afirmam que há concordância por parte dos pais. Muitas vezes, este acordo obtém-se através de formas aparentemente democráticas: "Na reunião de pais do início do ano, a associação põe a votação se o pais querem pagar todos o mesmo" (educadora JI B). No sentido de nos aproximarmos da realidade da rede solidária, recolhemos informação junto do jardim de infância que recebe o maior número de crianças (em média 92 crianças) e que aplica o referido despacho normativo. Da análise dos elementos verificamos que os valores médios do escalão 1 são inferiores a valores praticados nos jardins da rede pública. Estes valores contemplam os dois serviços da CAF - almoço e prolongamento - pelo que, em muitos casos, os aplicados na rede pública são também superiores aos pagos pelas crianças que se inscrevem no $2^{2}$ escalão. No caso do valor único, a situação é muito preocupante. $O$ que pode estar a acontecer é que as 
crianças provenientes de famílias economicamente mais desfavorecidas estejam a ser fortemente penalizadas em relação às crianças das classes média e média-alta. Ora, este facto introduz um efeito de $2^{a}$ ordem, (Ball, 2004) não esperado e altamente perverso, podendo ser uma das razões explicativas da procura da classe média pelos jardins de infância da rede pública e da transferência das crianças da rede solidária para a pública. Como referiu o dirigente da entidade parceira do jardim de infância de Astrolábio "algumas crianças estavam em privados, vieram para aqui" (EPA). Tentando compreender porque tal situação acontece, consideramos ser possível justificá-la pela presença de um conjunto de processos de multiregulação que se anulam entre si. Por outro lado, o facto de o governo autárquico não assumir "a coordenação da governação" da CAF de Mareantes e de a sua presença neste processo ser muito frágil favorece a presença deste efeito - desiguais condições de acesso em função dos rendimentos familiares. Por outro lado, consideramos que este efeito é também justificável pela ausência de uma análise política do texto da lei.

Neste estudo de caso, encontramos a sobreposição de diferentes lógicas, discursos, práticas e processos de micro e multirregulação na implementação da Política de Educação PréEscolar. $\mathrm{O}$ grande desafio que se coloca não está em restringir este espaço de regulação autónoma, mas de dar coerência Municipal e um sentido coletivo (da comunidade) a este projeto educativo e político.

\section{Considerações Finais}

Uma primeira conclusão que se retirou da análise das estatísticas nacionais disponíveis é a de que os governos nacionais ainda não conseguiram alcançar os objetivos traçados em 1997 no que concerne à universalização da EPE

Mesmo assim, terá que ser reconhecido o grande esforço feito, materializado num aumento de cerca de $20 \%$. No que respeita à relação do Estado com o terceiro setor, a nossa investigação revelou aspetos extremamente interessantes.

o discurso apelativo dos governos liderados por António Guterres, próximo da terceira via, parece ter sido entendido pelos representantes das instituições do terceiro setor, mas foi sempre questionado, nomeadamente, quanto às intenções governamentais. $O$ receio colocava-se a dois níveis: um, relacionado com a perda da sua autonomia, outro, relacionado com o financiamento das suas instituições. "Condenados a entenderem-se" é a expressão referida por um dos dirigentes que melhor exprime o sentido com que estes parceiros entraram no referido projeto. Se a avaliação que fazem da parceria nos dois primeiros ciclos de governação é positiva, o mesmo não acontece a partir daquele momento. As estruturas de diálogo e concertação deixaram de funcionar e começaram a surgir indicadores de desrespeito pelos compromissos assumidos, nomeadamente ao nível do planeamento da rede.

A CAF é uma medida híbrida, onde se jogam os interesses das famílias e das crianças. A forma como foi implementada no concelho, mobilizando parcerias com a sociedade civil, ampliou aquele hibridismo na medida em que se sobrepõem àqueles interesses e lógicas os das diferentes entidades parceiras. Este hibridismo ampliado dificultou a nossa análise dada a sua complexidade e ambiguidade. Verificamos problemas de relacionamento institucional, em especial num primeiro momento, que permitiram interpretações diferentes da medida, com especial impacto nas questões da qualidade, quer de natureza 
contextual, quer processual, e na promoção da igualdade de oportunidades de acesso das crianças. A ausência de mecanismos de acompanhamento, no que concerne à atribuição das comparticipações familiares, introduz um efeito altamente perverso no sistema. Estas perversidades do sistema exigem uma atenção especial dos líderes políticos. No jardim de infância público, através das parcerias estabelecidas, verificam-se lógicas de quasemercado, onde, entre outros aspetos, a disputa dos "clientes" começa a ser uma realidade.

\section{BIBLIOGRAPHY}

AFONSO, Almerindo Janela (2009), “Três Décadas de Políticas Educativas em Portugal (1975-2005)" in C. Reis; J. Boavida; J. Matos e V. Bento (Coord.), Escola: problemas e desafios, Guarda: Centro de Estudos Ibéricos: 13-29.

BALL, S.J. (1994), Educational reform: a critical and post-structural approach, Buckingham: Open University Press.

BALL, Stephen J. (2004), “Performatividade, Privatização e o Pós-Estado do Bem-Estar”, Educação \& Sociedade, vol. 25, nº 89: 1105-1126.

BALL, Stephen J. (2007), Education plc. Understanding private setor participation in public setor education, Londres: Routledge

BARROSO, João (2003), "Regulação e desregulação nas políticas educativas: tendências emergentes em estudos de educação comparada" in João Barroso (org.), A Escola Pública. Regulação. Desregulação. Privatização, Porto: ASA Ediç̧̃es: 19-48.

BOWE, Richard; BALL, Stephen J \& GOLD, Anne (1992), "The Policy Process and the process of policy" in R. Bowe; S. J. Ball, Reforming, Education and Changing Schools. Case Studies in Policy Sociology, Londres: Routledge: 6-23.

CHAMBOREDON, J. C \& PRÉVOT, J (1982), “O Ofício da Criança” in R. Grácio; S. Stoer \& S. Miranda (orgs.), Sociologia da Educação II - A Construção Social das Práticas Educativas, Lisboa: Livros Horizonte: 51-77.

DALE, Roger (1994), “A promoção do mercado educacional e polarização da educação”. Educação, Sociedade \& Culturas, n.. 2: 109-139.

GIDDENS, Anthony (1999), Para uma terceira via, Lisboa: Editorial Presença.

LIMA, Licínio (1992), A Escola como Organização e a Participação na Organização Escolar, Braga: Universidade do Minho. Centro de Estudos em Educação e Psicologia.

SARMENTO, Manuel J. (2003), ““”O Que Cabe na Mão...” Proposições para Uma Política Integrada da Infância" in D. Rodrigues (org.), Perspetivas Sobre a Inclusão. Da Educação à Sociedade, Porto: Porto Editora: 73-85.

VILARINHO, Maria Emília (2000), Políticas de Educação Pré-Escolar em Portugal (1977/1997),Lisboa: Instituto de Inovação Educacional. 
VILARINHO, Maria Emília (2011), o Estado e o Terceiro Setor na Construção das Políticas Educativas para a Infância em Portugal: o caso da Educação Pré-Escolar (1995-2010), Braga, Universidade do Minho [Tese de Doutoramento].

\section{NOTES}

1. Na aceção de Sarmento (2003).

2. Sobre a influência desta agenda teórica e política noutros níveis do sistema educativo português, ver

Afonso (2009).

3. Para uma análise mais detalhada ver Vilarinho, 2011.

4. Componente que integra o serviço de refeições e o prolongamento de horário com atividades de animação sócio-educativa.

\section{ABSTRACTS}

Neste artigo pretendemos analisar, criticamente, o processo de definição e implementação do novo projeto político para a Educação Pré-Escolar, iniciado com a publicação da sua Lei-Quadro (Lei n.. 5/97, de 10 de fevereiro). Destacaremos, em particular, as parcerias entre o Estado e o Terceiro Setor na expansão da oferta educativa e na aplicação do novo modelo de serviços. Identificaremos a emergência de novos papéis assumidos pelo Estado, a sua nova forma de atuação e o novo padrão de governação deste nível de educação. Por fim, discutiremos os efeitos produzidos por estas alterações na promoção do direito das crianças a uma educação de qualidade.

In this article we pretend to analyze, critically, the definition and implementation process of the new political project for the Pre-School Education, initiated with the publication of the Law no 5/97, 10 February. We will highlight, in particular, the partnerships between the State and the Third Setor to expand the educational offer and to implement the new model of services. We will identify the emergence of new roles assumed by the State, its new form of action, and a new pattern of governance at this level of education. Finally, we will discuss the effects produced by these changes in promoting the rights of the children to a quality education.

Dans ce texte, nous nous proposons d'analyser, de façon critique, le processus de définition et de mise en oeuvre du nouveau projet politique pour l'éducation préscolaire, qui a débuté avec la publication de la loi-cadre (Loi n. 5/97, du 10 février). On met en évidence, en particulier, les partenariats entre l'état et le secteur tertiaire dans l'expansion de l'offre éducative et à la mise en oeuvre du nouveau modèle d'appuis. Nous soulignons l'émergence de nouveaux rôles assumés par l'état, sa nouvelle forme d'actuation et le nouveau cadre de gouvernance de ce niveau d'enseignement. Finalement, nous discutons les effets produits par ces changements dans la promotion des droits des enfants à une éducation de qualité. 
INDEX

Mots-clés: éducation préscolaire, état, secteur tertiaire, partenariats, troisième voie

Keywords: Pre-School education, state, third setor, partnerships, third way

Palavras-chave: educação Pré-Escolar, estado, terceiro setor, parcerias, terceira via

\section{AUTHOR}

\section{EMÍLIA VILARINHO}

Professora do Departamento de Ciências Sociais da Educação, Instituto de Educação, Universidade do Minho,

evilarinho@ie.uminho.pt 